\title{
Role of pH in the Aqueous Phase Reactivity of Zerovalent Iron Nanoparticles with Acid Orange 7, a Model Molecule of Azo Dyes
}

\author{
F. S. Freyria, ${ }^{1,2}$ S. Esposito, ${ }^{3}$ M. Armandi, ${ }^{1}$ F. Deorsola, ${ }^{1}$ E. Garrone, ${ }^{1}$ and B. Bonelli ${ }^{1}$ \\ ${ }^{1}$ Department of Applied Science and Technology and INSTM Unit of Torino-Politecnico, Corso Duca degli Abruzzi 24, \\ Politecnico di Torino, 10129 Turin, Italy \\ ${ }^{2}$ Department of Chemistry, Massachusetts Institute of Technology, 77 Massachusetts Ave., Cambridge, MA 02139, USA \\ ${ }^{3}$ Department of Civil and Mechanical Engineering, Università degli Studi di Cassino e del Lazio Meridionale, Via G. Di Biasio 43, \\ 03043 Cassino, Italy
}

Correspondence should be addressed to B. Bonelli; barbara.bonelli@polito.it

Received 2 February 2017; Accepted 30 April 2017; Published 11 June 2017

Academic Editor: Vincenzo Baglio

Copyright (c) 2017 F. S. Freyria et al. This is an open access article distributed under the Creative Commons Attribution License, which permits unrestricted use, distribution, and reproduction in any medium, provided the original work is properly cited.

The effect of both $\mathrm{pH}$ and surface oxidation of nanoparticles is studied on the interaction between a commercial slurry of Nanoscale Zerovalent Iron (NZVI) and the azo dye Acid Orange 7 (AO7). NZVI is a reducing agent used for the degradation of several pollutants, including azo dyes: during pollutant degradation, it undergoes progressive oxidation and dissolution. Though it is generally acknowledged that NZVI consists of core-shell nanoparticles, where the core of metallic iron is covered by $\mathrm{Fe}_{x} \mathrm{O}_{y}$ shell, it still remains a poorly defined system. In this work, the solid fraction recovered by filtration and drying was characterized by means of XRD diffraction with Rietveld refinement, $\mathrm{N}_{2}$ isotherms at $77 \mathrm{~K}$, FE-SEM and TEM observation, EDX analysis, and IR spectroscopy. Powders were obtained from both the parent slurry and the same slurry pretreated with $\mathrm{HCl}$ in order to remove $\mathrm{Fe}_{x} \mathrm{O}_{y}$ shell, finally reactivating the nanoparticles. The aforementioned physicochemical characterization allowed figuring out some correlations between the properties of the studied nanomaterial and the processes occurring when it is in contact with AO7 in aqueous phase. The type of interaction occurring within the NZVI/AO7 system (adsorption and type of redox reactions) strongly depends not only on the $\mathrm{pH}$ of the starting solution, but also on the surface oxidation of the nanoparticles.

\section{Introduction}

Synthetic dyes are used in many fields, such as textile, plastic, cosmetic, and tannery industries: approximately 800.000 tons of dyes are produced every year all over the world, their global demand being predicted yet to grow in the next years [1-4].

Azo dyes featuring at least one diazo bond $(-\mathrm{N}=\mathrm{N}-)$ in the structure constitute almost $50 \%$ of the total, and over $15 \%$ of the produced amount ends up into effluents after dyeing treatments $[5,6]$. Their removal from water streams is therefore a major environmental concern, since azo dyes are harmful both to humans and to the aquatic life [1, 7]. Being recalcitrant to natural degradation, several technologies have been developed for remediation of both streams and wastewaters, including photocatalytic degradation $[6,8-11]$, advanced oxidation processes [12-18], adsorption [19-23], ion flotation [24], and sedimentation [25]. Unfortunately, physicochemical treatments are often expensive, and biological approaches are typically slow and poorly efficient [2628].

In the last decade, much interest has been devoted to Nanoscale Zerovalent Iron (NZVI) [29], acting as a reducing agent for several pollutants, while undergoing oxidation and dissolution [30-38]. The use of metallic iron in environmental remediation, indeed, dates back to the midseventies, when it was used as filling reactive material in the Permeable Reactive Barrier technology for reductive dechlorination of halogenated hydrocarbons $[39,40]$. This ability has prompted the use of iron particles, ranging from millimetric to nanometric scale, for degradation of other contaminants [41], 


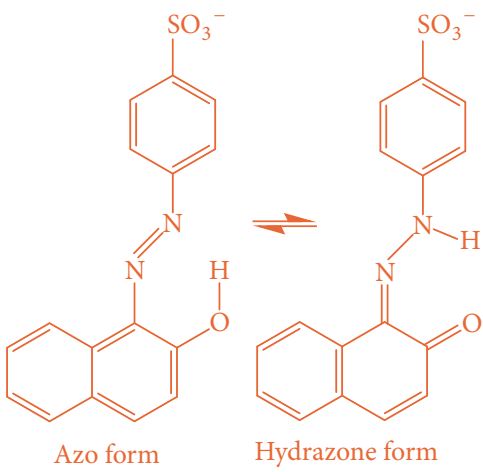

(a)

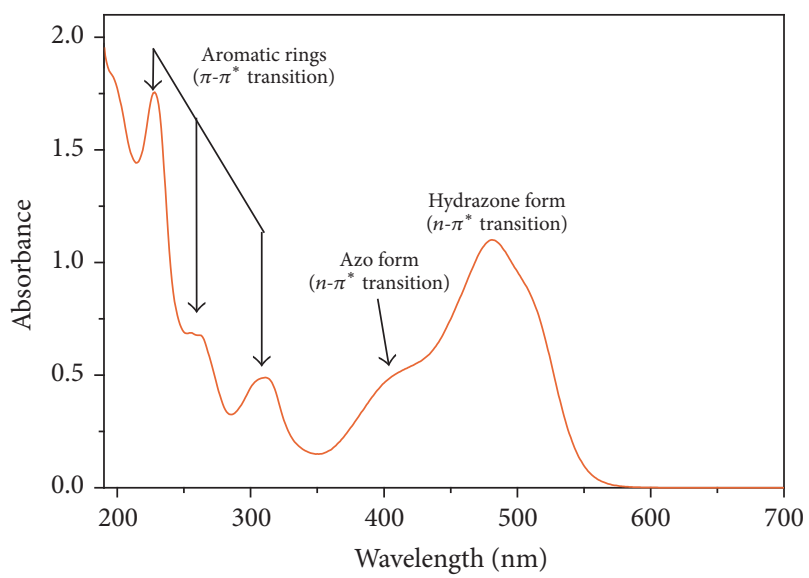

(b)

SCHEME 1: Section (a): azo-hydrazo tautomerism of AO7 in water. Section (b): UV-Vis spectrum of 0.67 mM AO7 aqueous solution.

including pesticides [42, 43], nitroaromatics [44], metal ions $[31,36,39,45]$, and dyes [30, 46-52].

For on field environmental applications, industrial quantities of NZVI slurries are, however, necessary: in the past, Toda Kogyo Corp. was the only company producing industrial quantities of NZVI slurries under the name of RNIP (Reactive Nanoscale Iron Particles), whereas more recently other companies started NZVI production [53].

Whatever its source, NZVI remains, so far, a poorly characterized system, normally consisting of an aqueous slurry featuring a solid phase and, possibly, a stabilizer [30].

As it concerns the solid phase, physicochemical characterization by means of several microscopic and spectroscopic techniques determined that NZVI mainly consists of coreshell particles, with a core of $\alpha-\mathrm{Fe}^{0}$ particles and an outer shell of $\mathrm{Fe}_{x} \mathrm{O}_{y}$ [54-57]. The shell consists of mixed $\mathrm{Fe}^{2+} / \mathrm{Fe}^{3+}$ oxides, usually richer in $\mathrm{Fe}^{3+}$ ions (i.e., more oxidized) at the water/shell interface $[58,59]$. On the one hand, totally oxidized surfaces (i.e., where only $\mathrm{Fe}^{3+}$ ions occur) result in inactive towards pollutants degradation; on the other hand the core-shell structure is fundamental for reactivity, as both the defectiveness and disorder of $\mathrm{Fe}_{x} \mathrm{O}_{y}$ layer make NZVI more active than bulk iron materials covered by "nondefective"-oxide layers [59]. The reaction mechanism acknowledged by the literature for the process of contaminant removal encompasses both the metallic iron core, acting as the electron source, and the oxide shell [38], facilitating sorption of contaminants while ensuring electrons transport from the metal core to the target contaminant [60-62].

In a previous paper [30], we investigated the degradation of the azo dye Acid Orange 7 (AO7, Scheme 1) by two RNIP suspensions commercialized at $\mathrm{pH}$ values around 12 . Those experiments were run in slightly basic conditions, as obtained after adding RNIP to a water solution of $0.67 \mathrm{mM}$ $\mathrm{AO} 7$ (the latter having a natural $\mathrm{pH}$ equal to 6.8, i.e., close to neutrality). The performance of RNIP suspensions towards $\mathrm{AO} 7$ degradation resulted to depend on both aging (i.e., nanoparticles oxidation by exposure to air) and the presence of a protective organic polymer in one of them. The mechanism of interaction with AO7 was instead affected by the degree of surface oxidation [30]. In summary, on oxidized (aged) surfaces, mere adsorption of AO7 moieties took place and surface oxidation was partially prevented in polymer protected RNIP, which was able to degrade AO7 through the complex redox mechanism reported in Scheme 3.

Surface oxidation occurs normally as a consequence of aging, not only decreasing NZVI efficiency in remediation, but also modifying its toxicity towards earthworms and other organisms $[63,64]$. For this reason, in this work we studied a slurry treated with $\mathrm{HCl}$ with the purpose of (partially/totally) removing the oxide shell, eventually promoting the activity of inner metallic iron.

Concerning $\mathrm{pH}$ of the aqueous phase, another important parameter affecting remediation efficiency, other slurries are commercialized at nearly neutral $\mathrm{pH}$ values. The role of $\mathrm{pH}$ is crucial, as it may influence both the reactivity with the pollutants and the actual composition of NZVI. In this work, the overall role of $\mathrm{pH}$ in the reactions of $\mathrm{AO} 7$ with NZVI is investigated, with the purpose of drawing a comprehensive picture of the reactivity of the NZVI/AO7 system, in comparison with previous work where the degradation of $\mathrm{AO} 7$ was studied in basic conditions [30].

\section{Materials and Methods}

2.1. Materials and Physicochemical Characterization. The slurry (commercial name: NANOFER 25, provided by Nano Iron Future Technology, Czech Republic) was studied both as received and after 12 months. Both slurries were stored in a fridge to preserve their properties by preventing/slowing down oxidation phenomena, but in the latter case, the bottle was opened in order to study the effect of aging by natural oxidation in atmospheric conditions.

On the fresh slurry, an acidic treatment was carried out by sonication of $c a$. $0.204 \mathrm{~g}$ slurry for $5 \mathrm{~min}$, followed by filtration and washing with $5.0 \mathrm{~mL}$ of $1.0 \mathrm{M} \mathrm{HCl}$ solution and final drying. 
For NPs physicochemical characterization, solid fractions were collected by filtrating the slurry (Anopore inorganic membrane with $0.02 \mu \mathrm{m}$ pore size, Whatman), washing the solid with acetone, and drying in air at ambient conditions [55].

The corresponding powder samples will be referred to as $\mathrm{Fe}$ _fresh and $\mathrm{Fe}$ _aged (for the solids recovered from the asreceived slurry and after 12 months) and as $\mathrm{Fe}$ fresh- $\mathrm{HCl}$ (for the solid obtained after $\mathrm{HCl}$ treatment).

The physicochemical properties of the solids were characterized as follows:

(i) Powders XRD patterns were measured on an X'Pert Philips diffractometer (PANalytical B.V.), using $\mathrm{Cu}$ $\mathrm{K}_{\alpha}$ radiation in the $10^{\circ}-90^{\circ} 2 \theta$ range (step width $=$ $0.02^{\circ} 2 \theta$; time per step $12 \mathrm{~s}$ ). The obtained diffraction patterns were indexed according to PDF-2 Release 2002 database. The corresponding contents of ZVI and of $\mathrm{Fe}$ oxo/hydroxide phases were determined by full-profile Rietveld method by using the GSASEXPGUI software [65].

(ii) Field Emission Scanning Microscopy (FE-SEM) pictures were collected on a high resolution instrument (LEO 1525) equipped with a Gemini Field Emission Column and an Energy Dispersive X-ray (EDX) probe for semiquantitative chemical analysis (low vacuum scanning electron microscope Quanta inspect 200).

(iii) Transmission Electron Microscopy (TEM) analysis was carried out on a TEM JEM 2011 instrument operating at $200 \mathrm{kV}$.

(iv) Specific surface area was calculated according to the BET (Brunauer-Emmett-Teller) method by $\mathrm{N}_{2}$ sorption isotherms at $-196^{\circ} \mathrm{C}$ measured on samples previously outgassed at $120^{\circ} \mathrm{C}$ for $4 \mathrm{~h}$ to remove water and other atmospheric contaminants (Quantachrome Autosorb 1 instrument).

(v) Fourier Transform-IR (FT-IR) spectra of powders (both before and after AO7 degradation) were collected at $2 \mathrm{~cm}^{-1}$ resolution in the $4000-500 \mathrm{~cm}^{-1}$ range on a Bruker Equinox 55 FT-IR spectrophotometer, equipped with a MCT (Mercury Cadmium Telluride) detector. For FT-IR measurements, powders were mixed with optical-grade $\mathrm{KBr}$ (weight ratio $\mathrm{Fe}: \mathrm{KBr}=1: 50)$.

2.2. AO7 Degradation Experiments. The starting $0.67 \mathrm{mM}$ AO7 solution was obtained by dissolving AO7 (Standard Fluka, Italy) in doubly distilled water (Carlo Erba, Italy): the natural $\mathrm{pH}$ of the solution was 6.8. The corresponding UVVis spectrum in water (Scheme 1(b)): the peaks at $310 \mathrm{~nm}$ and $230 \mathrm{~nm}$ (and the shoulder at $260 \mathrm{~nm}$ ) are due to aromatic ring absorptions. The peak at $484 \mathrm{~nm}$ is due to $n-\pi^{*}$ transition involving the lone pair of $\mathrm{N}$ atoms at the conjugated system extending over the two aromatic moieties and encompassing the N-N group of the hydrazone form $[5,52,66]$.

The shoulder at $403 \mathrm{~nm}$ has a similar nature, involving the N-N group of the azo form [8]. Degradation experiments were run either at natural $\mathrm{pH}$ of the solution (6.8) or by adjusting it to $10.0,8.0,4.0$, and 2.0 by adding proper amounts of either $0.01 \mathrm{M} \mathrm{NaOH}$ or $0.01 \mathrm{M} \mathrm{HCl}$. The latter solutions were prepared by dissolving either $\mathrm{NaOH}$ (anhydrous pellets from BioXtra, Italy, with purity $\geq 98 \%$ ) or hydrochloric acid (37\% w/w, ACS reagent, Sigma Aldrich, Italy) in doubly distilled water (Carlo Erba, Italy).

The interaction of AO7 with NZVI samples was studied in air at room temperature by adding $0.5-1 \mathrm{~g} \mathrm{~L}^{-1} \mathrm{NZVI}$ dispersion to $400 \mathrm{ml}$ of $0.67 \mathrm{mM} \mathrm{AO7}$ solution, then by stirring with an orbital shaker (MPM instruments). Before reaction, the NZVI dispersions were sonicated for $c a .5$ minutes in order to favour NPs dispersion.

Aliquots of the suspension were collected at different time intervals and the supernatant solution was separated by centrifugation (ALC centrifuge PK110, at $4000 \mathrm{rpm}$ for 2 minutes). After each sampling, the UV-Vis spectrum of the supernatant was recorded in the $190-800 \mathrm{~nm}$ range on a Cary 5000 spectrophotometer (Varian instrument), equipped with a quartz cell with $1 \mathrm{~mm}$ path length.

The (residual) concentration of AO7 in the supernatant was evaluated by the intensity of the band at $484 \mathrm{~nm}$, related to the dye hydrazone form in equilibrium with the azo form in water, as depicted in Scheme 1.

To have first-hand spectroscopic data concerning 1amino-2-naphthol (1A2N), one of the possible products of AO7 degradation [5], the corresponding chlorhydrate (Merck) was dissolved in water, and its UV-Vis spectrum was taken over a wide $\mathrm{pH}$ range. This procedure allowed us to discriminate between the spectrum of the neutral form, the protonated one, and the anionic one (Figure SI1 in Supplementary Material available online at https://doi.org/10.1155/2017/2749575). Similarly, the possibility also investigated that $1 \mathrm{~A} 2 \mathrm{~N}$ may form complexes with either $\mathrm{Fe}^{3+}$ or $\mathrm{Fe}^{2+}$ ions in solution, by taking UV-Vis spectra in the presence of such cations (Figure SI2).

\section{Results and Discussion}

3.1. Physicochemical Characterization of the Solid Fraction. Figure 1 reports XRD patterns of samples both before (sections (a), (b), and (c)) and after reaction (sections (d) and (e)): the peaks due to $\alpha-\mathrm{Fe}^{0}$ and $\mathrm{Fe}_{3} \mathrm{O}_{4}$ phases are observed with all the samples. Additional peaks ascribable to another phase (vide infra) are observed to occur in the $\mathrm{Fe}$ f fresh- $\mathrm{HCl}$ powder after reaction.

Table 1 reports samples phase composition (wt.\%), as obtained by Rietveld refinements: before reaction, $\alpha-\mathrm{Fe}^{0}$ is the dominant phase, although it slightly decreases in the aged sample. Treatment with $\mathrm{HCl}$ brings about an apparent increase in the content of metallic iron, due to the dissolution of the basic oxide $\mathrm{Fe}_{3} \mathrm{O}_{4(\mathrm{~s})}$ :

$$
\mathrm{Fe}_{3} \mathrm{O}_{4}+8 \mathrm{HCl} \longrightarrow \mathrm{Fe}^{2+}+2 \mathrm{Fe}^{3+} 4 \mathrm{H}_{2} \mathrm{O}+8 \mathrm{Cl}^{-}
$$

With $\mathrm{Fe}$ fresh-HCl after reaction, also peaks due to lepidocrocite $(\gamma-\mathrm{FeO}(\mathrm{OH}))$ are observed (Figure $1(\mathrm{e}))$ : removal of $\mathrm{Fe}_{3} \mathrm{O}_{4}$ by acidic treatment allows exposure of "fresh" $\alpha$-Fe surface which readily reacts in water, by forming $\mathrm{FeO}(\mathrm{OH})$ as previously observed in the literature $[30,61]$. A minor amount 


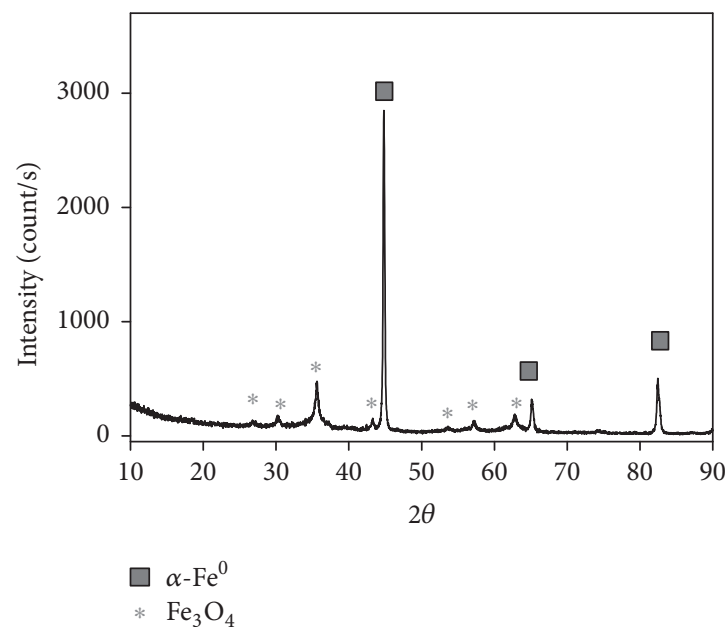

(a)

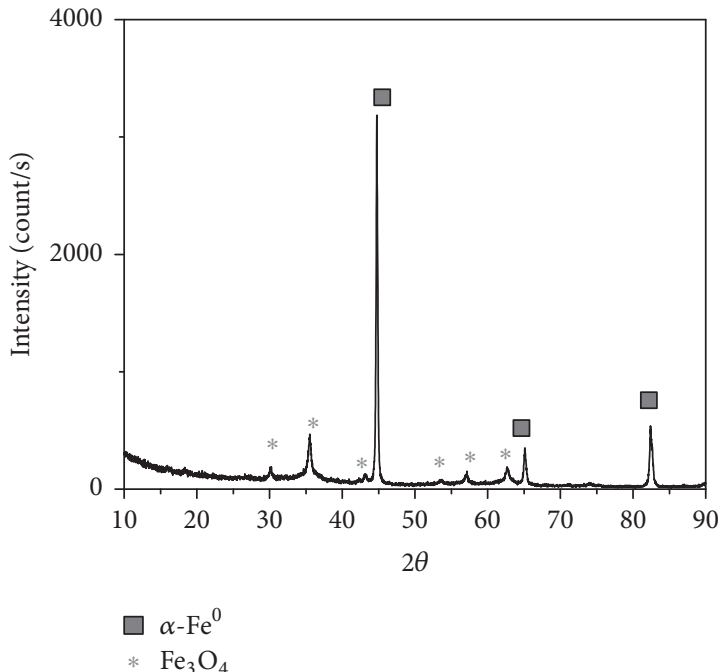

(c)

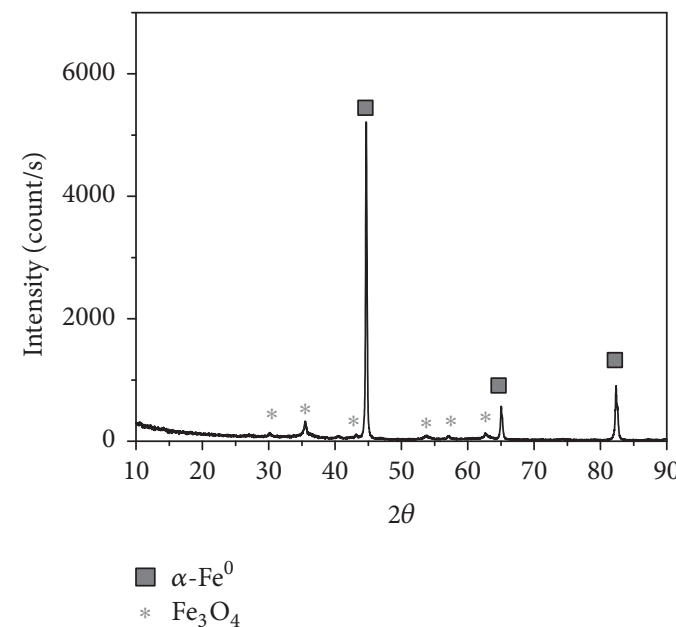

(b)

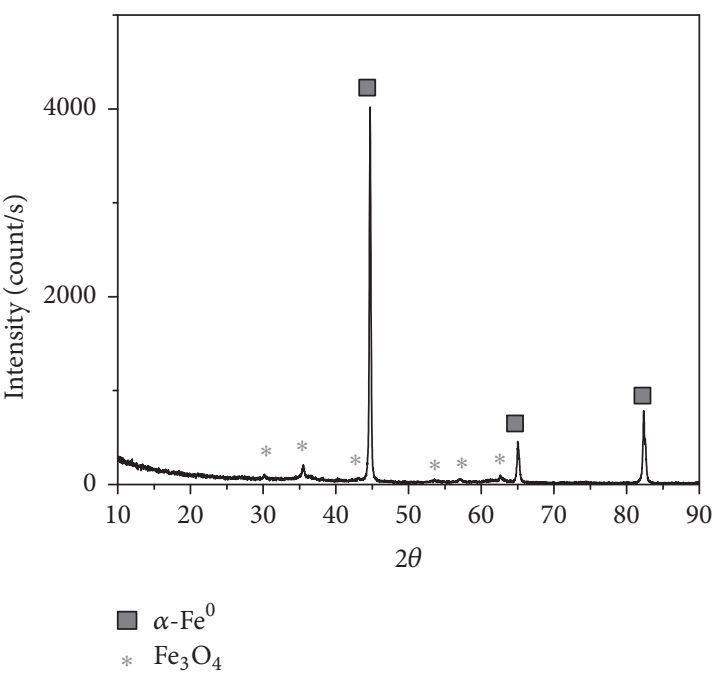

(d)

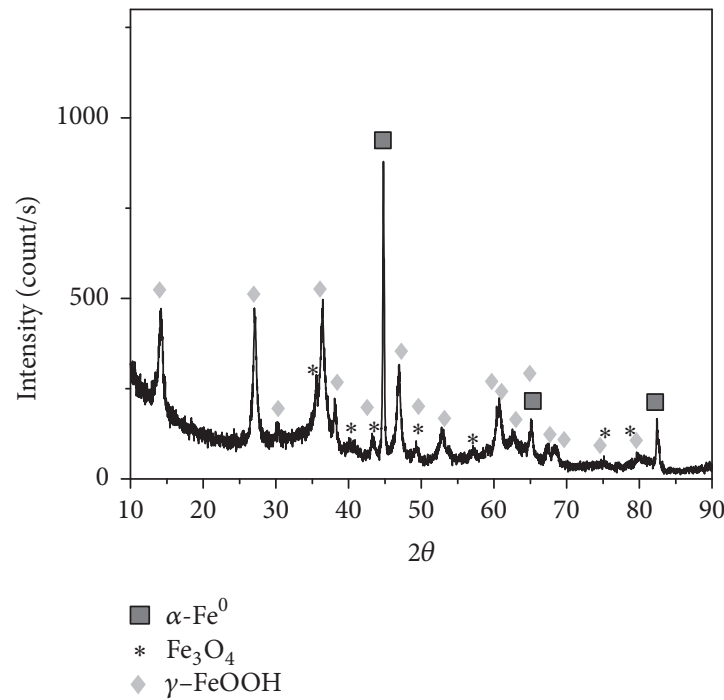

(e)

FIGURE 1: Powders XRD patterns of the following samples: section (a) Fe_fresh; section (b) Fe_aged; section (c) Fe_fresh_HCl; section (d) $\mathrm{Fe}$ fresh after reaction; section (e) Fe_fresh-HCl after reaction. 


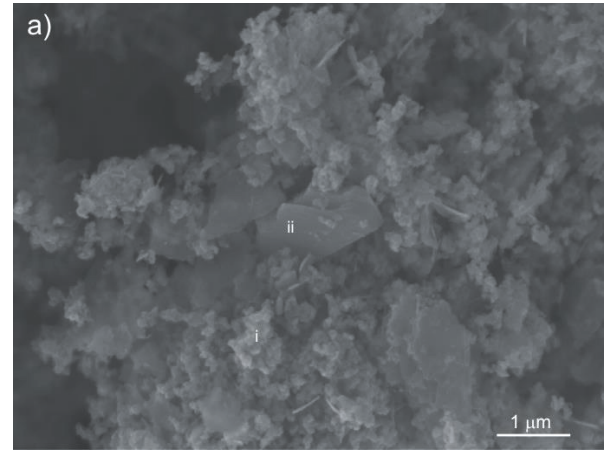

(a)

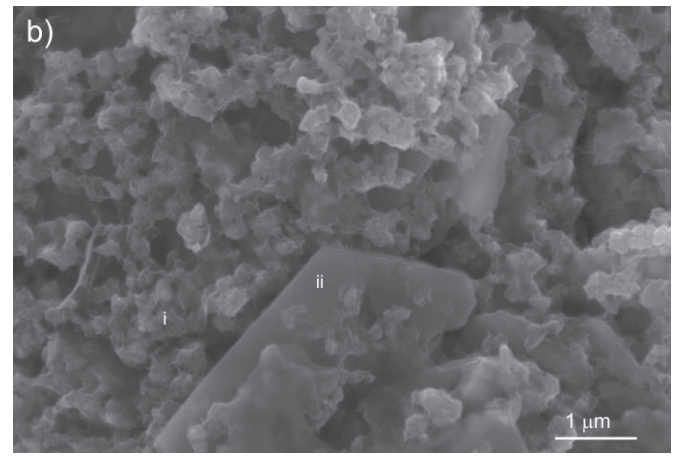

(b)

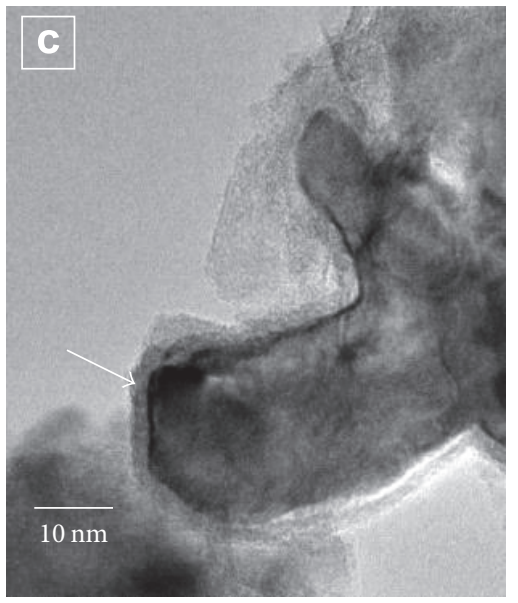

(c)

FIGURE 2: Selected FE-SEM micrographs of sample Fe_fresh (section (a)) and Fe_fresh-HCl (section (b)). Selected TEM micrograph of sample Fe_fresh (section (c)).

TABLE 1: BET specific surface area (SSA) values as obtained by $\mathrm{N}_{2}$ sorption isotherms at $-196^{\circ} \mathrm{C}$ and calculated phase composition (\% by weight) as obtained by Rietveld refinement.

\begin{tabular}{|c|c|c|c|}
\hline Sample & $\begin{array}{l}\text { BET SSA } \\
\left(\mathrm{m}^{2} \mathrm{~g}^{-1}\right)\end{array}$ & $\begin{array}{c}\text { Phase } \\
\text { composition (\% } \\
\text { by weight) }\end{array}$ & $\begin{array}{c}\text { Phase } \\
\text { composition } \\
\text { after reaction } \\
\text { (\% by weight) }\end{array}$ \\
\hline \multirow{2}{*}{$\mathrm{Fe} \_$fresh } & \multirow{2}{*}{60} & $\begin{array}{c}\alpha-\mathrm{Fe} \\
80.08 \pm 0.13\end{array}$ & $\begin{array}{c}\alpha-\mathrm{Fe} \\
77.06 \pm 0.19\end{array}$ \\
\hline & & $\begin{array}{c}\mathrm{Fe}_{3} \mathrm{O}_{4} \\
19.92 \pm 0.76\end{array}$ & $\begin{array}{c}\mathrm{Fe}_{3} \mathrm{O}_{4} \\
22.41 \pm 0.80\end{array}$ \\
\hline \multirow{3}{*}{$\begin{array}{l}\mathrm{Fe} \text { ffresh- } \\
\mathrm{HCl}\end{array}$} & \multirow{3}{*}{93} & $\begin{array}{c}\alpha-\mathrm{Fe} \\
87.09 \pm 0.14\end{array}$ & $\begin{array}{c}\alpha-\mathrm{Fe} \\
26.59 \pm 0.61\end{array}$ \\
\hline & & $\mathrm{Fe}_{3} \mathrm{O}_{4}$ & $\begin{array}{c}\mathrm{Fe}_{3} \mathrm{O}_{4} \\
3.54 \pm 0.99\end{array}$ \\
\hline & & $12.91 \pm 0.82$ & $\begin{array}{c}\gamma \text {-FeOOH } \\
69.87 \pm 0.45 \\
\end{array}$ \\
\hline \multirow{2}{*}{$\mathrm{Fe}$ aged } & \multirow{2}{*}{56} & $\begin{array}{c}\alpha-\mathrm{Fe} \\
76.23 \pm 0.17\end{array}$ & - \\
\hline & & $\begin{array}{c}\mathrm{Fe}_{3} \mathrm{O}_{4} \\
23.77 \pm 0.69\end{array}$ & - \\
\hline
\end{tabular}

of $\mathrm{Fe}_{3} \mathrm{O}_{4}$ is still present after $\mathrm{HCl}$ treatment: the latter is likely a thin layer of magnetite that, acting as a semiconductor, could facilitate both charge transport within the layer and total oxidation of $\mathrm{Fe}^{2+}$ to $\mathrm{Fe}^{3+}$ species during reaction with AO7 and with dissolved oxygen, since the reaction mixtures were not deaerated $[59,67]$.

Morphological analysis of the samples (before reaction) was carried by means of both FE-SEM and TEM techniques. Figure 2(a) reports a FE-SEM micrograph of Fe_fresh where two families of particles were observed. Particles labelled as (i) are nearly spherical, with an average diameter of $110 \mathrm{~nm}$ and an iron and oxygen content of about 52 at.\% and 38 at.\%, respectively, as measured by EDX analysis, indicating that they are partially oxidized (vide infra). Particles (ii) are instead much larger and characterized by a platelet shape, with iron and oxygen contents of about 38 at.\% and 52 at.\%, respectively, that is, a chemical composition very close to that of magnetite $\left(\mathrm{Fe}_{3} \mathrm{O}_{4}\right)$.

Figure 2(b) reports a FE-SEM micrograph of Fe_fresh$\mathrm{HCl}$ sample: particles (i) have undergone slight morphology changes, appearing after $\mathrm{HCl}$ treatment with a more irregular shape; particles (ii) look almost unaffected by the acidic treatment. Figure 2(c) reports a TEM magnification of sample 


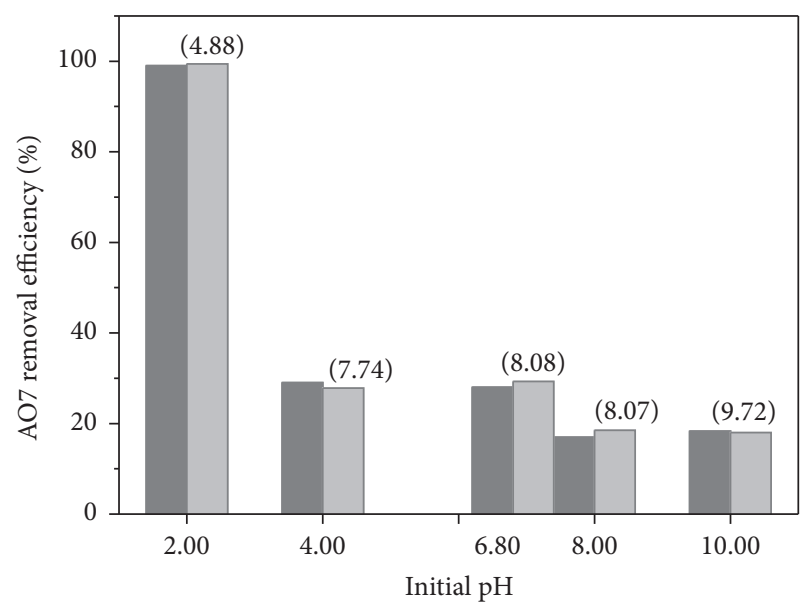

$15 \mathrm{~min}$

$60 \mathrm{~min}$

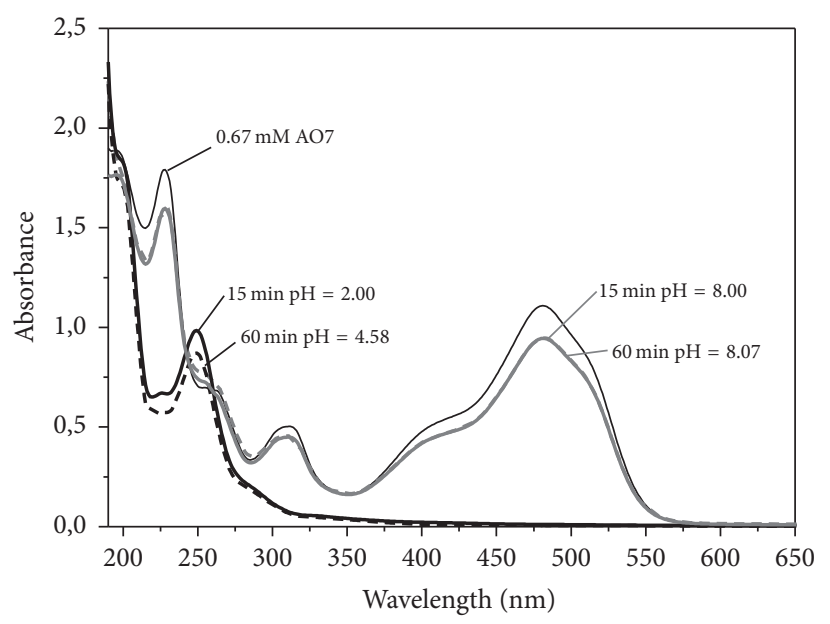

(b)

FIGURE 3: Section (a): removal efficiency of AO7 (\%) obtained with sample Fe_fresh at different initial pH values after 15 min (grey columns) and $60 \mathrm{~min}$ (light grey columns); numbers in parenthesis refer to $\mathrm{pH}$ values measured after $60 \mathrm{~min}$. Section (b): UV-Vis spectra of $0.67 \mathrm{mM}$ $\mathrm{AO} 7$ solution and of the supernatant solutions after $15 \mathrm{~min}$ and $60 \mathrm{~min}$ at both $\mathrm{pH}=8.00$ (grey curves) and $\mathrm{pH}=2.00$ (black curves).

Fe_fresh, where (i) particles characterized by a metallic (darker) core surrounded by a brighter shell (arrow) can be appreciated. Morphological analysis in Figure 2 suggests that both larger magnetite particles and core-shell particles occur in the Fe_fresh sample, as previously observed with RNIP [15]. Larger magnetite particles are likely present due to the kind of synthesis: the formation of fully oxidized particles for aging would be expected on the smaller particles, which undergo full oxidation first.

$\mathrm{N}_{2}$ sorption isotherms at $77 \mathrm{~K}$ (not reported) were of type II for all the studied samples, as typical of nonporous materials. The corresponding BET specific surface area values, reported in Table 1, show that the surface area of Fe_fresh and Fe_aged samples does not differ much, indicating that it was almost unaffected by aging, whereas it markedly increased after treatment with $\mathrm{HCl}$. This phenomenon was likely due to the formation of some porosity and/or surface roughness during reaction (1).

As a whole, aging has a limited effect on both surface area and phase composition, as determined by XRD: the aged sample (stored in the fridge, vide supra) shows a composition as similar as the as-received sample. $\mathrm{HCl}$ treatment, instead, markedly changes the surface properties of the studied materials, which contain both core-shell NPs and larger particles of magnetite.

3.2. Effect of $\mathrm{pH}$ on the Reactivity with AO7. Due to the poor effect of aging on both surface area and composition (Table 1), sample Fe_aged was not considered for AO7 degradation experiments, and only the interaction between $\mathrm{Fe}$ ffresh and AO7 was studied.

The effect of $\mathrm{pH}$ on the process in water was considered by studying the phenomenon either at the natural $\mathrm{pH}$ of AO7 solution $(=6.8)$ or after bringing $\mathrm{pH}$ to $2.0,4.0,8.0$, and
10.0 , the $484 \mathrm{~nm}$ band of the dye being used to measure the concentration of residual $\mathrm{AO} 7$ in the supernatant solution.

Figure 3(a) reports efficiency towards $\mathrm{AO} 7$ removal measured as the percentage of decrease of the $484 \mathrm{~nm}$ band at different $\mathrm{pH}$ values after 15 and 60 min of contact, $\mathrm{pH}$ values after $60 \mathrm{~min}$ being reported in parenthesis. It can be noticed that the effect of starting $\mathrm{pH}$ is substantial, as the AO7 removal efficiency ranges from ca. 20\% (in basic conditions) to $100 \%$ (in acidic conditions). Nonetheless, in acidic conditions the supernatant solution $\mathrm{pH}$ increases with time, whereas it remains almost constant (or slightly decreases) in basic conditions, so indicating the occurrence of different processes. This may be appreciated in Figure 3(b) reporting the UV-Vis spectra of the supernatant solutions obtained at $\mathrm{pH}=2.0$ and $\mathrm{pH}=8.0$ after 15 and $60 \mathrm{~min}$ contact with $\mathrm{Fe}$ _fresh. In slightly basic conditions, the overall spectrum of $\mathrm{AO} 7$ decreases, without formation of any other band, indicating that mere adsorption takes place, and indeed UV-Vis spectra recorded after 15 and 60 min nearly coincide. The behaviour at $\mathrm{pH}=10.0$ is entirely similar (spectra not reported). Concerning AO7 adsorption, it must be considered that the point of zero charge (PZC) of magnetite is 6.8, so at higher $\mathrm{pH}$, as in the present cases, the particles surface is negatively charged, and adsorption may only occur through some uncoordinated iron ions at the surface of Fe_fresh. Such ions may interact with the sulphonic group of the dye and/or coordinate $\mathrm{N}$ atoms of the azo bond, in agreement with the literature $[68,69]$. Since AO7 molecules may not adsorb on fully oxidized (i.e., $\mathrm{Fe}_{2} \mathrm{O}_{3}$ ) surfaces [30], interaction most probably involves $\mathrm{Fe}^{2+}$ surface ions of the magnetite phase.

The experiment run at the initial $\mathrm{pH}$ of 2.0 has different features, in that a redox process is implied: the band at $484 \mathrm{~nm}$ disappears, while a band at $c a$. $249 \mathrm{~nm}$, with a shoulder at $280 \mathrm{~nm}$, firstly grows (after $15 \mathrm{~min}$, black continuous line 

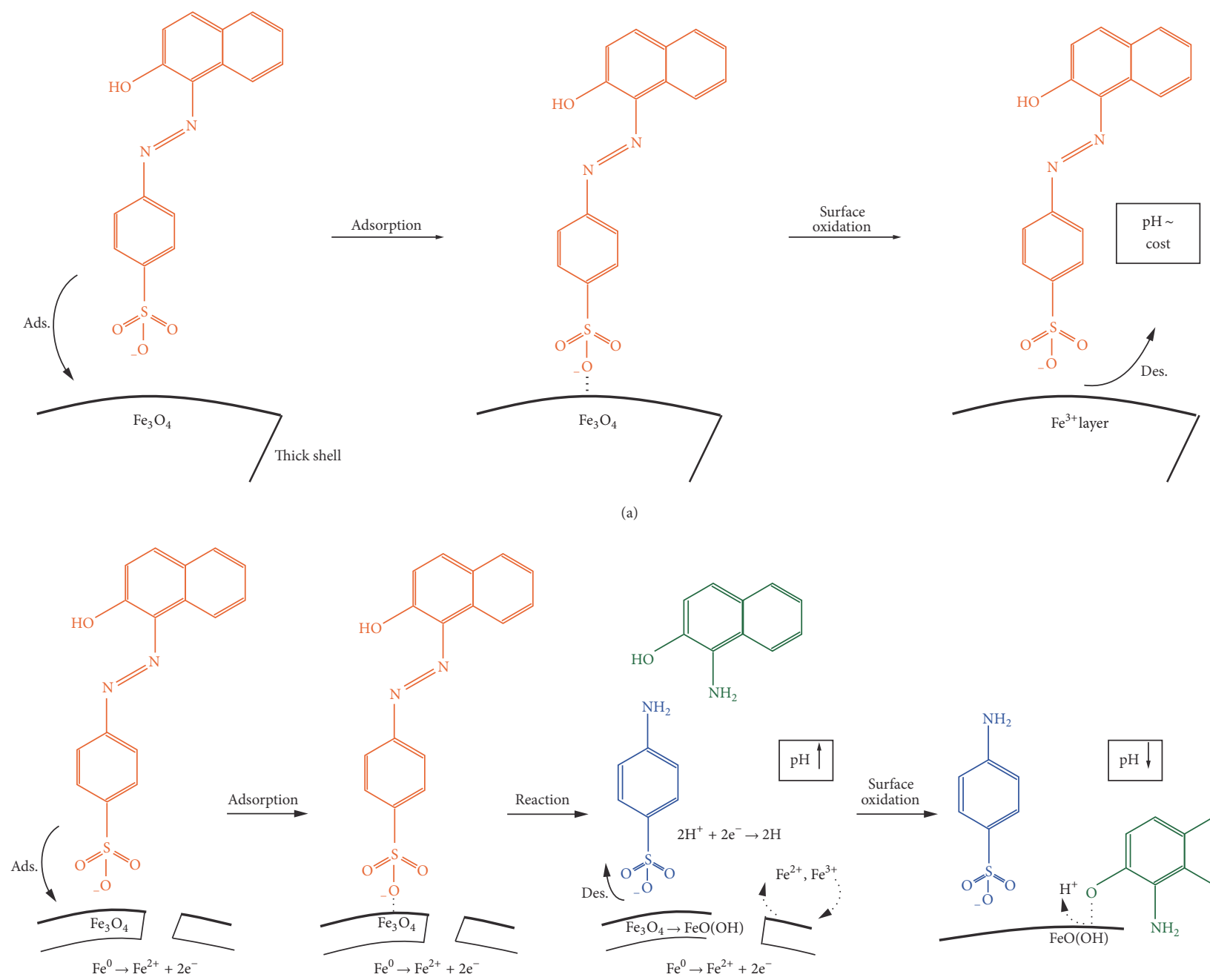

(a)

SCHEme 2: Mechanism of AO7 degradation in aqueous solution by means of Fe_fresh particles (section (a)) and Fe_fresh-HCl particles (section (b)).

in Figure 3(b)) and then decreases somewhat (after $60 \mathrm{~min}$, black dashed line in Figure 3(b)). As shown in Scheme 3, the expected products of the reaction between $\mathrm{AO} 7$ and metallic iron in acidic conditions are sulphanilic acid (SA) and $1 \mathrm{~A} 2 \mathrm{~N}$, arising from the reductive cleavage of the azo bond. Unfortunately, both substances (as well as many other organics) absorb around $250 \mathrm{~nm}$. In detail, SA in solution shows both a band at $c a .245 \mathrm{~nm}$ and a shoulder at $285 \mathrm{~nm} .1 \mathrm{~A} 2 \mathrm{~N}$ is reported to show a band at $228 \mathrm{~nm}$ [5], not observed in this case. Instead, in the separate experiment described in SI, the band for protonated $1 \mathrm{~A} 2 \mathrm{~N}$ was measured at $245-250 \mathrm{~nm}$, shifting to $257 \mathrm{~nm}$ in basic conditions. We are therefore inclined to ascribe the band at $c a .250 \mathrm{~nm}$ mainly to $1 \mathrm{~A} 2 \mathrm{~N}$. Being $\mathrm{p} K_{\mathrm{a}}$ of SA equal to 3.23 , the moiety in solution should be protonated at the beginning of the reaction and deprotonated at $\mathrm{pH}=$ 4.58 , so that after $60 \mathrm{~min}$ reaction it should adsorb at the surface of $\mathrm{Fe}$ _fresh through the sulphonic group, from which the observed decrease in intensity of the band at $c a .249 \mathrm{~nm}$. It is noteworthy that $1 \mathrm{~A} 2 \mathrm{~N}$ is not adsorbed on Fe_fresh NPs in the present conditions. In the following, it will be shown that adsorption of $1 \mathrm{~A} 2 \mathrm{~N}$ may be observed under different circumstances.

The reaction in acidic conditions was accompanied by a marked increase in $\mathrm{pH}$, due to consumption of hydronium ions. Two mechanisms may be envisaged for this process. The reduction of $\mathrm{AO} 7$ is described for simplicity in Scheme 2 as implying $\mathrm{H}$ atoms. Indeed, as already suggested in the literature $[46,50]$, hydronium ions are removed from solution, and electrons are provided by metallic iron, which can form in the first instance $\mathrm{Fe}^{2+}$ species:

$$
\mathrm{Fe}^{0}+2 \mathrm{H}^{+} \longrightarrow \mathrm{Fe}^{2+}+2 \mathrm{H}
$$

Taking into account the fact that 4 hydronium ions are consumed per $\mathrm{AO} 7$ molecule, the change in $\mathrm{pH}$ expected on the basis of reaction (2) results to be much less than what observed. Another more extensive mechanism for the consumption of hydronium ions most probably consists in the attack of the (basic) solid $\mathrm{Fe}_{3} \mathrm{O}_{4}$ by hydronium ions, the 


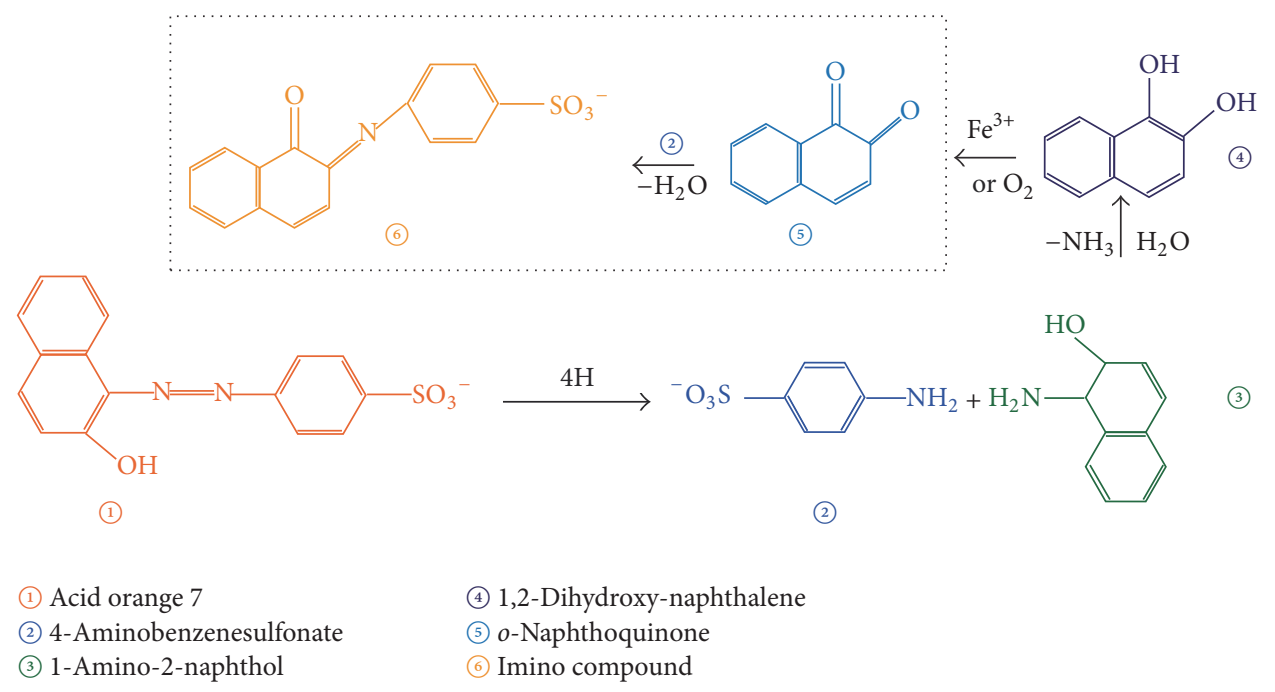

Scheme 3: Mechanism of AO7 degradation by NZVI particles in aqueous solution. Dotted framed reaction takes place only in presence of polymer modified NZVI particles described in [15].

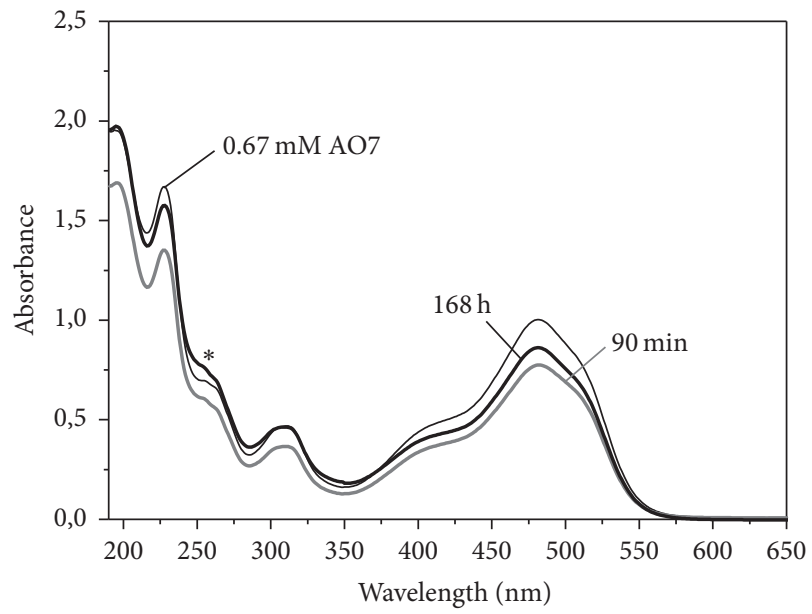

(a)

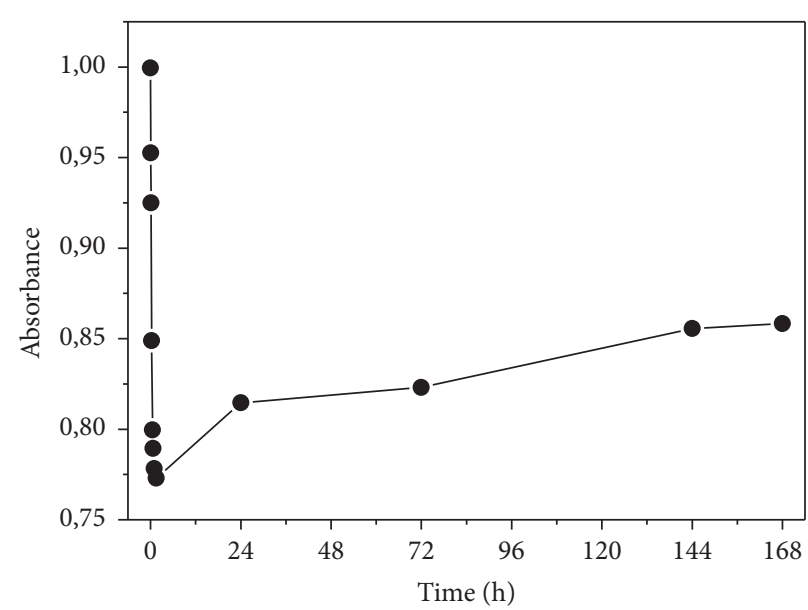

(b)

FIGURE 4: Section (a): UV-Vis spectra of $0.67 \mathrm{mM} \mathrm{AO7}$ solution and of the supernatant solutions in contact with $\mathrm{Fe}$ _fresh at $\mathrm{pH}=6.80$ after $90 \mathrm{~min}$ (grey curve) and after $168 \mathrm{~h}$ (black curve). Section (b): trend in the intensity of the AO7 band at $484 \mathrm{~nm}$ as a function of time.

same reaction occurring during reactivation of aged samples by $\mathrm{HCl}$ solutions:

$$
\begin{aligned}
\mathrm{Fe}_{3} \mathrm{O}_{4}(\mathrm{~s})+8 \mathrm{H}^{+}(\mathrm{aq}) \longrightarrow & \mathrm{Fe}^{2+}(\mathrm{aq})+2 \mathrm{Fe}^{3+}(\mathrm{aq}) \\
& +4 \mathrm{H}_{2} \mathrm{O}
\end{aligned}
$$

yielding both ferrous and ferric ions in solution.

Finally, the experiments run at initial $\mathrm{pH}$ values of 4.0 and 6.8 yielded UV-Vis spectra (not reported) similar to those observed at basic $\mathrm{pH}$ values, so showing that the process is adsorption of AO7. The moderate increase in $\mathrm{pH}$ along the reaction, however, indicates that reaction (2) is also taking place (vide infra), providing fresh surfaces for adsorption, and thus yielding a removal efficiency above $20 \%$.

In summary, as depicted in Scheme 2, with basic solutions simple adsorption takes place. With $\mathrm{pH}$ values close to neutrality, adsorption is also the predominant process, but acidic attack to the magnetite surface takes place, finally providing new anchoring points for AO7 molecules. With acidic solutions, the erosion of the oxide layer is extensive enough to activate the chemistry of metallic iron, so that the phenomenon switches from the mere adsorption of AO7 to cleavage of the azo bond, with probably firstly adsorption of $\mathrm{SA}$ and release of $1 \mathrm{~A} 2 \mathrm{~N}$ into the solution.

3.3. Long-Term Behaviour of $\mathrm{Fe}$ fresh. At the natural $\mathrm{pH}$ of the solution only, further evolution of the system was observed at longer times with Fe_fresh: Figure 4(a) shows a minimum in the intensity of the $484 \mathrm{~nm}$ band after 90 minutes reaction, corresponding to a decrease around $24 \%$. At $\mathrm{pH}=6.80$ adsorption is the main phenomenon taking place, although some reaction occurs, in agreement with both 


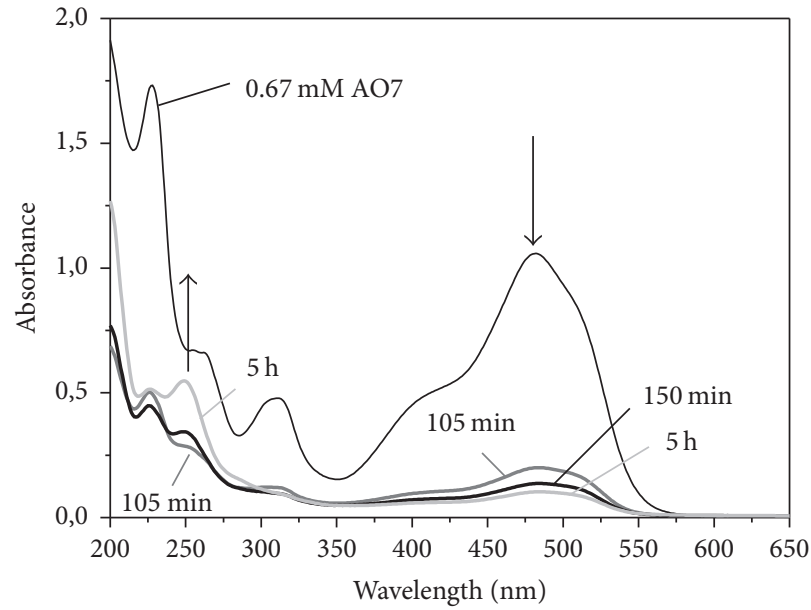

(a)

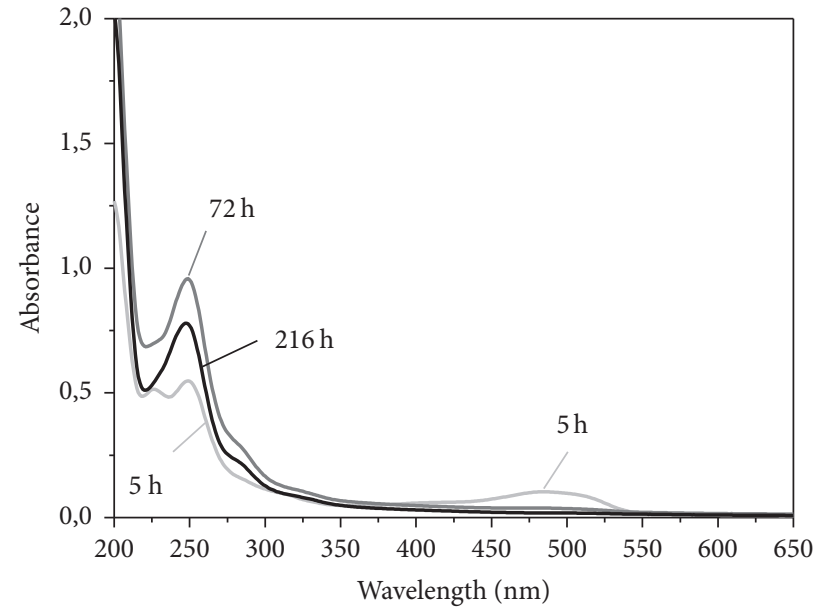

(b)

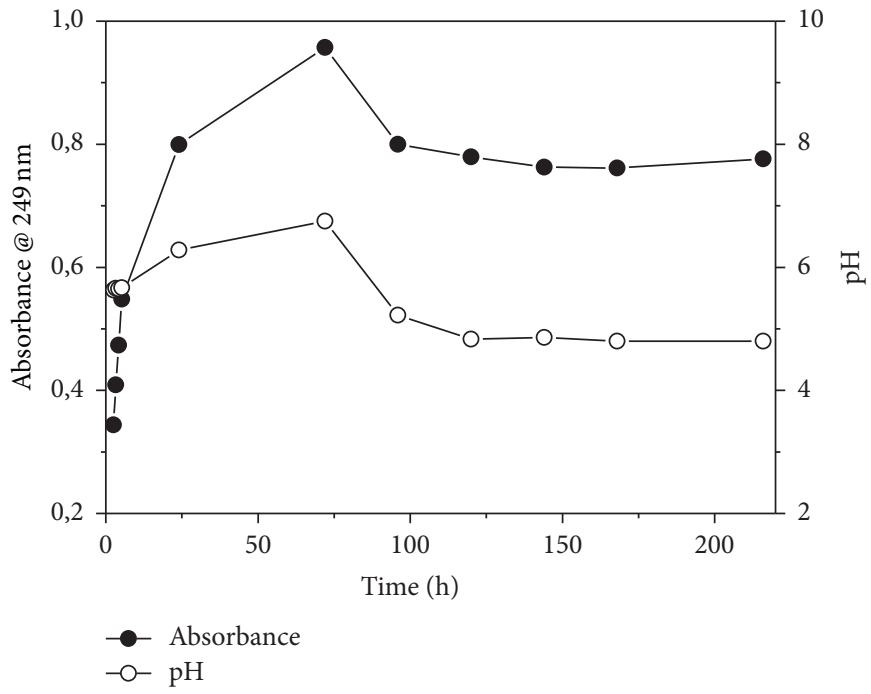

(c)

Figure 5: Section (a): UV-Vis spectra of $0.67 \mathrm{mM}$ AO7 solution and of the supernatant solutions in contact with $\mathrm{Fe}$-fresh-HCl sample at pH $=6.80 \mathrm{after} 105 \mathrm{~min}$ (grey curve), $150 \mathrm{~min}$ (black curve), and $5 \mathrm{~h}$ (light grey curve). Section (b): selected UV-Vis spectra of the supernatant solutions after $5 \mathrm{~h}$ (light grey curve), $72 \mathrm{~h}$ (grey curve), and $216 \mathrm{~h}$ (black curve). Section (c): trend in the intensity of the $1 \mathrm{~A} 2 \mathrm{~N}$ band at $249 \mathrm{~nm}$ (black symbols) and of $\mathrm{pH}$ (white symbols) as a function of time.

the observed increase in $\mathrm{pH}$ and the increased absorption at $249 \mathrm{~nm}$ (asterisk) due to the azo bond cleavage described above. Figure 4(b) shows that, at longer contact times, the intensity of the $484 \mathrm{~nm}$ band increases again and after $168 \mathrm{~h}$ the overall decrease is $c a .15 \%$. Such an apparent "reversible phenomenon" may be ascribed to further oxidation of the surface from magnetite to $\mathrm{Fe}^{3+}$ oxo-hydroxides, causing desorption of $\mathrm{AO} 7$, which does not adsorb on fully oxidized surfaces [30].

3.4. Behaviour of Reactivated Samples. With samples reactivated by $\mathrm{HCl}$, two types of experiments were run, one at nearly neutral $\mathrm{pH}$ and the other at $\mathrm{pH}=10$.

Figure 5 describes the experiment at nearly neutral $\mathrm{pH}$ : spectra recorded within the first 105 minutes show a plain decrease in intensity (with an overall decrease around $80 \%$, section (a)). No new bands were observed, so suggesting again the occurrence of a mere adsorption process.

After 150 minutes, a band at $c a .249 \mathrm{~nm}$ was observed to grow as in Figure 3(b) (black curve in Figure 5(a)), reaching its maximum after 72 hours, then decreasing in intensity, and finally reaching a plateau (Figure 5(b)). Interestingly, the solution $\mathrm{pH}$ followed the same trend, reaching after 72 hours the highest value at 6.8 and then decreasing to 4.8 within $216 \mathrm{~h}$ (Figure 5(c)).

The second stage of the process seems to correspond to the cleavage of the azo bond, and indeed the $\mathrm{pH}$ increases because protons are consumed. Simultaneously, however, oxidation of the surface takes place, beyond the formation of 
magnetite, likely yielding lepidocrocite [5], probably through the agency of some dissolved oxygen:

$$
2 \mathrm{Fe}_{3} \mathrm{O}_{4(\mathrm{~s})}+\frac{1}{2} \mathrm{O}_{2(\mathrm{aq})}+3 \mathrm{H}_{2} \mathrm{O}_{(\mathrm{l})} \longrightarrow 6 \gamma \mathrm{FeO}(\mathrm{OH})_{(\mathrm{s})}
$$

The surface so becomes unable to host SA, which is adsorbed on magnetite, but not on more oxidized surfaces (in the present case lepidocrocite).

In contrast, $1 \mathrm{~A} 2 \mathrm{~N}$ appears to have affinity for the fully oxidized surface and to adsorb by releasing the phenolic proton. This accounts for the decrease in $\mathrm{pH}$ in the latter stages of reaction.

Two facts are worth of note. On the one hand, the acidity of phenolic groups may markedly increase by effect of substituents. On the other hand, the $1 \mathrm{~A} 2 \mathrm{~N}$ anion given rise may behave as a bidentate ligand because of the simultaneous presence of $-\mathrm{NH}_{2}$ and the phenolic $\mathrm{O}^{-}$species, whereas SA only features the sulphonic group as a docking moiety, apparently able to interact with $\mathrm{Fe}^{2+}$ ions, but not with $\mathrm{Fe}^{3+}$ ones. The presence in the liquid phase of SA accounts for the presence of a plateau in Figure 5(b). Experiments run with $\mathrm{Fe} \_$fresh- $\mathrm{HCl}$ at $\mathrm{pH}=10$ showed similar features (Figures not reported).

It is now appropriate to make a comparison with the reactivity in slightly basic solutions, that is, with the RNIP slurries studied in a previous paper [15], the overall chemistry observed being reported in Scheme 3. RNIP promotes the cleavage of azo group in basic conditions [15]: with particularly active (polymer protected) RNIP samples, the $1 \mathrm{~A} 2 \mathrm{~N}$ given rise partially further oxidizes to $o$-naphthoquinone, which condenses back with SA to yield a molecule close in structure to AO7, so mimicking a partial reversal of the degradation reaction.

It is worth noting that such reaction is not observed with the samples studied in this work. The question arises whether a basic nature of the solution is required. Separate experiments, reported in Figure SI2, showed that the 1A2N molecule, when allowed to stand in a basic solution, does not show reactions as in Scheme 3, that is, the substitution of the amino group with a hydroxyl species. Much more vital seems to be the nature of the surface, which provides sites for the ligand displacement: it is not straightforward, however, to propose a more detailed explanation.

IR spectra of powders outgassed at room temperature were recorded before and after interaction with $\mathrm{AO} 7$ solution in order to further investigate the presence of adsorbed species: Figure 6 reports difference spectra of both Fe_fresh and $\mathrm{Fe}$ _fresh-HCl samples after reaction obtained by subtraction of the corresponding spectra before interaction with AO7. It should be noticed that the slope of the curves is simply due to some scattering phenomena and that, being difference spectra reported, positive bands are due to species formed after interaction with $\mathrm{AO}$, whereas negative bands are due to bands disappeared after such interaction.

In the lower wavenumbers region, bands between 630 and $530 \mathrm{~cm}^{-1}$ are assigned to $\mathrm{Fe}-\mathrm{O}$ symmetric stretching modes [70, 71]. The characteristic bands of lepidocrocite $(\gamma-$ $\mathrm{FeO}(\mathrm{OH}))[5]$ at 1157,1020 , and $749 \mathrm{~cm}^{-1}$ are observed in the

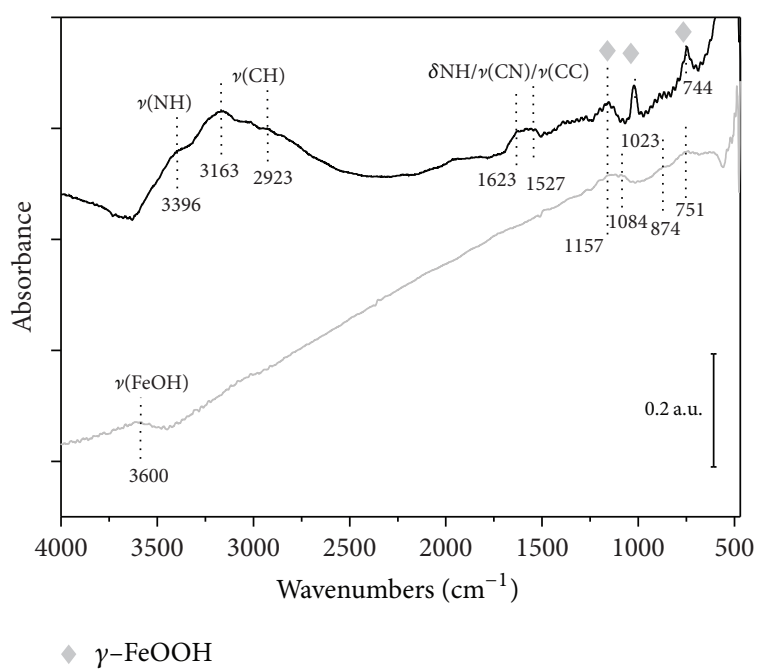

FIGURE 6: IR spectra of $\mathrm{Fe} \_$fresh (grey curve) and $\mathrm{Fe}$ _fresh- $\mathrm{HCl}$ after reaction, obtained by subtraction of the IR spectra of the corresponding samples before reaction.

IR spectrum of $\mathrm{Fe} \_$fresh-HCl (black curve), in fair agreement with the previously discussed results; both samples exhibited signals at $c a .1090,900$, and $750 \mathrm{~cm}^{-1}$, likely due to presence of other iron oxy-hydroxide surface species [5].

No bands ascribable to adsorbed AO7 molecules are seen with $\mathrm{Fe}$ ffresh (grey curve), in agreement with the observed desorption of $\mathrm{AO} 7$ from oxidized surfaces. The IR spectrum concerning Fe_fresh-HCl (black curve) shows instead bands in the $3600-2800 \mathrm{~cm}^{-1}$ and in the $1640-1540 \mathrm{~cm}^{-1}$ range: the former are assigned to $\mathrm{NH}$ - stretching and bending vibration of adsorbed species [72]; no bands ascribable to sulphonic groups modes, usually absorbing at $1250-1140 \mathrm{~cm}^{-1}$ (asymmetric stretching vibration) and $1070-1030 \mathrm{~cm}^{-1}$ (symmetric stretching vibration), are observed [8], in agreement with the previous hypothesis of desorption of SA and adsorption of $1 \mathrm{~A} 2 \mathrm{~N}$ on more oxidized surfaces, as suggested in Scheme 2(b).

\section{Conclusions}

The type of interaction between Acid Orange 7 and Nanoscale Zerovalent Iron mostly depends on surface composition of the solid nanoparticles and $\mathrm{pH}$ of the aqueous phase.

Concerning surface oxidation of iron nanoparticles, two main results are obtained: (i) exposure to air does not lead to remarkable iron oxidation, likely because the slurry was kept in a fridge, the low temperature definitely preventing iron oxidation, and (ii) treatment with $\mathrm{HCl}$ satisfactorily restores nanoparticles reactivity towards Acid Orange 7, by the likely dissolution of the outer magnetite layer. Surface oxidation is an important issue, in that when only $\mathrm{Fe}_{3} \mathrm{O}_{4}$ is available adsorption of the dye is the dominant type of interaction in this system. The same result was obtained by some of us in a previous work where another Nanoscale Zerovalent Iron commercialized at basic $\mathrm{pH}$ was studied (Reactive Nanoscale Iron Particles). 
In the presence of (reactive) core-shell nanoparticles, cleavage of $\mathrm{N}=\mathrm{N}$ bond occurs: such phenomenon leads to different reaction products depending on $\mathrm{pH}$ of the aqueous phase.

In the present work, where a slurry commercialized at nearly neutral $\mathrm{pH}$ was employed, lowering the $\mathrm{pH}$ led to a remarkable enhancement of dye removal. The reaction basically consists in the hydrogenation cleavage of the $\mathrm{N}=\mathrm{N}$ bond, but in acidic condition, the source of hydrogen atoms seems to be the reaction $n \mathrm{H}^{+}+\mathrm{Fe}^{0} \rightarrow n \mathrm{H}+\mathrm{Fe}^{n+}$ and indeed the $\mathrm{pH}$ is observed to increase during the process. The resulting products (sulphanilic acid and 1-amino-2-naphthol) are rather stable and suffer a different fate, as sulphanilic acid is firstly adsorbed, and 1-amino-2-naphthol is in solution and only adsorbs when the surface is thoroughly oxidized.

With Reactive Nanoscale Iron Particles, instead, the cleavage of azo group was possible also in strongly basic conditions (Scheme 3). Moreover, with the polymer protected Reactive Nanoscale Iron Particles, the produced 1-amino-2naphthol partially further oxidizes to $o$-naphthoquinone and condenses back with sulphanilic acid to yield a molecule close in structure to Acid Orange 7, then mimicking a partial reversal of the degradation reaction. Such reaction seems to be typical of the polymer protected Reactive Nanoscale Iron Particles, as it is not observed with Nanoscale Zerovalent Iron particles studied in the present paper.

\section{Conflicts of Interest}

The authors declare that there are no conflicts of interest regarding the publication of this paper.

\section{Acknowledgments}

The authors thank Professor M. Piumetti (Politecnico di Torino) for his support during IR spectroscopy measurements, Professor R. Sethi (Politecnico di Torino, Italy) and Professor G. Viscardi (Università degli Studi di Torino, Italy), for providing NANOFER 25 dispersion and 1-amino-2naphthol-chlorhydrate powder, respectively, and Dr. Sandra Casale (Universitè Pierre et Marie Curie, France) for TEM measurements.

\section{References}

[1] T. Satapanajaru, C. Chompuchan, P. Suntornchot, and P. Pengthamkeerati, "Enhancing decolorization of Reactive Black 5 and Reactive Red 198 during nano zerovalent iron treatment," Desalination, vol. 266, no. 1-3, pp. 218-230, 2011.

[2] L. Ayed, K. Bekir, S. Achour, A. Cheref, and A. Bakhrouf, "Exploring bioaugmentation strategies for azo dye CI Reactive Violet 5 decolourization using bacterial mixture: dye response surface methodology," Water and Environment Journal, vol. 31, no. 1, pp. 80-89, 2017.

[3] R. L. Singh, P. K. Singh, and R. P. Singh, "Enzymatic decolorization and degradation of azo dyes - A review," International Biodeterioration and Biodegradation, vol. 104, pp. 21-31, 2015.

[4] X. Zhang, Y. Wu, G. Xiao et al., "Simultaneous photocatalytic and microbial degradation of dye-containing wastewater by a novel g- $\mathrm{C}_{3} \mathrm{~N}_{4}-\mathrm{P}_{25}$ /photosynthetic bacteria composite," PLoS ONE, vol. 12, no. 3, pp. 1-16, 2017.

[5] J. A. Mielczarski, G. M. Atenas, and E. Mielczarski, "Role of iron surface oxidation layers in decomposition of azo-dye water pollutants in weak acidic solutions," Applied Catalysis B: Environmental, vol. 56, no. 4, pp. 289-303, 2005.

[6] C. Ponraj and J. Daniel, "A review on the visible light active $\mathrm{BiFeO}_{3}$ nanostructures as suitable photocatalyst in the degradation of different textile dyes," Environmental Nanotechnology, Monitoring \& Management, 2017.

[7] M. A. Rauf, M. A. Meetani, and S. Hisaindee, "An overview on the photocatalytic degradation of azo dyes in the presence of $\mathrm{TiO}_{2}$ doped with selective transition metals," Desalination, vol. 276, no. 1-3, pp. 13-27, 2011.

[8] C. Bauer, P. Jacques, and A. Kalt, "Photooxidation of an azo dye induced by visible light incident on the surface of TiO2," Journal of Photochemistry and Photobiology A: Chemistry, vol. 140, no. 1, pp. 87-92, 2001.

[9] C. Bauer, P. Jacques, and A. Kalt, "Investigation of the interaction between a sulfonated azo dye (AO7) and a $\mathrm{TiO} 2$ surface," Chemical Physics Letters, vol. 307, no. 5-6, pp. 397-406, 1999.

[10] A. R. Khataee and M. B. Kasiri, "Photocatalytic degradation of organic dyes in the presence of nanostructured titanium dioxide: influence of the chemical structure of dyes," Journal of Molecular Catalysis A: Chemical, vol. 328, no. 1-2, pp. 8-26, 2010.

[11] F. Petronella, A. Truppi, C. Ingrosso et al., "Nanocomposite materials for photocatalytic degradation of pollutants," Catalysis Today, vol. 281, pp. 85-100, 2017.

[12] J. J. Pignatello, E. Oliveros, and A. MacKay, "Advanced oxidation processes for organic contaminant destruction based on the Fenton reaction and related chemistry," Critical Reviews in Environmental Science and Technology, vol. 36, no. 1, pp. 1-84, 2006.

[13] M. Piumetti, F. S. Freyria, M. Armandi et al., "Catalytic degradation of Acid Orange 7 by $\mathrm{H}_{2} \mathrm{O}_{2}$ as promoted by either bare or V-loaded titania under UV light, in dark conditions, and after incubating the catalysts in ascorbic acid," Catalysis, Structure \& Reactivity, vol. 1, no. 4, pp. 183-191, 2015.

[14] M. Piumetti, F. S. Freyria, M. Armandi, G. Saracco, E. Garrone, and B. Bonelli, "Anti-oxidant / pro-oxidant activity of ascorbic acid," Chem. Today, vol. 33, no. April, pp. 13-15, 2015.

[15] M. Piumetti, F. S. Freyria, M. Armandi, F. Geobaldo, E. Garrone, and B. Bonelli, "Fe- and V-doped mesoporous titania prepared by direct synthesis: Characterization and role in the oxidation of AO7 by $\mathrm{H} 2 \mathrm{O} 2$ in the dark," Catalysis Today, vol. 227, pp. 71-79, 2014.

[16] F. S. Freyria, M. Armandi, M. Compagnoni, G. Ramis, I. Rossetti, and B. Bonelli, "Catalytic and Photocatalytic Processes for the Abatement of N-Containing Pollutants From Wastewater. Part 2: Organic Pollutants," J. Nanosci. Nanotechnol, vol. 17, no. 3654-3672, 2017.

[17] J. Chen, L. Zhang, T. Huang, W. Li, Y. Wang, and Z. Wang, "Decolorization of azo dye by peroxymonosulfate activated by carbon nanotube: Radical versus non-radical mechanism," Journal of Hazardous Materials, vol. 320, pp. 571-580, 2016.

[18] J. Wang, S. Dong, C. Yu, X. Han, J. Guo, and J. Sun, "An efficient $\mathrm{MoO}_{3}$ catalyst for in-practical degradation of dye wastewater under room conditions," Catalysis Communications, vol. 92, pp. 100-104, 2017.

[19] D. Sun, X. Zhang, Y. Wu, and X. Liu, "Adsorption of anionic dyes from aqueous solution on fly ash," Journal of Hazardous Materials, vol. 181, no. 1-3, pp. 335-342, 2010. 
[20] F. Sannino, S. Ruocco, A. Marocco, S. Esposito, and M. Pansini, "Cyclic process of simazine removal from waters by adsorption on zeolite H-Y and its regeneration by thermal treatment," Journal of Hazardous Materials, vol. 229-230, pp. 354-360, 2012.

[21] L. Li, Z. Shi, H. Zhu, W. Hong, F. Xie, and K. Sun, "Adsorption of azo dyes from aqueous solution by the hybrid MOFs/GO," Water Science and Technology, vol. 73, no. 7, pp. 1728-1737, 2016.

[22] T. Shen, J. Luo, S. Zhang, and X. Luo, "Hierarchically mesostructured MIL-101 metal-organic frameworks with different mineralizing agents for adsorptive removal of methyl orange and methylene blue from aqueous solution," Journal of Environmental Chemical Engineering, vol. 3, no. 2, pp. 1372-1383, 2015.

[23] S. Dadfarnia, A. M. Haji Shabani, S. E. Moradi, and S. Emami, "Methyl red removal from water by iron based metal-organic frameworks loaded onto iron oxide nanoparticle adsorbent," Applied Surface Science, vol. 330, pp. 85-93, 2015.

[24] K. Shakir, A. F. Elkafrawy, H. F. Ghoneimy, S. G. Elrab Beheir, and M. Refaat, "Removal of rhodamine B (a basic dye) and thoron (an acidic dye) from dilute aqueous solutions and wastewater simulants by ion flotation," Water Research, vol. 44, no. 5, pp. 1449-1461, 2010.

[25] S. Zodi, O. Potier, F. Lapicque, and J.-P. Leclerc, "Treatment of the industrial wastewaters by electrocoagulation: Optimization of coupled electrochemical and sedimentation processes," Desalination, vol. 261, no. 1-2, pp. 186-190, 2010.

[26] Y.-T. Lin, C.-H. Weng, and F.-Y. Chen, "Effective removal of AB24 dye by nano/micro-size zero-valent iron," Separation and Purification Technology, vol. 64, no. 1, pp. 26-30, 2008.

[27] J. Qi, C. E. Paul, F. Hollmann, and D. Tischler, "Changing the electron donor improves azoreductase dye degrading activity at neutral pH," Enzyme and Microbial Technology, vol. 100, pp. 1719, 2017.

[28] R. G. Saratale, G. D. Saratale, J. S. Chang, and S. P. Govindwar, "Bacterial decolorization and degradation of azo dyes: a review," Journal of the Taiwan Institute of Chemical Engineers, vol. 42, no. 1, pp. 138-157, 2011.

[29] T. Tosco, M. Petrangeli Papini, C. Cruz Viggi, and R. Sethi, "Nanoscale zerovalent iron particles for groundwater remediation: A review," Journal of Cleaner Production, vol. 77, pp. 10-21, 2014.

[30] F. S. Freyria, B. Bonelli, R. Sethi, M. Armandi, E. Belluso, and E. Garrone, "Reactions of acid orange 7 with iron nanoparticles in aqueous solutions," Journal of Physical Chemistry C, vol. 115, no. 49, pp. 24143-24152, 2011.

[31] C. Noubactep and S. Caré, "On nanoscale metallic iron for groundwater remediation," Journal of Hazardous Materials, vol. 182, no. 1-3, pp. 923-927, 2010.

[32] N. C. Mueller, J. Braun, J. Bruns et al., "Application of nanoscale zero valent iron (NZVI) for groundwater remediation in Europe," Environmental Science and Pollution Research, vol. 19, no. 2, pp. 550-558, 2012.

[33] Y. Liu and G. V. Lowry, "Effect of particle age (Fe0 content) and solution $\mathrm{pH}$ on NZVI reactivity: $\mathrm{H} 2$ evolution and TCE dechlorination," Environmental Science and Technology, vol. 40, no. 19, pp. 6085-6090, 2006.

[34] S. Bae and K. Hanna, "Reactivity of Nanoscale Zero-Valent Iron in Unbuffered Systems: Effect of pH and Fe(II) Dissolution," Environmental Science and Technology, vol. 49, no. 17, pp. 1053610543, 2015.

[35] H.-S. Kim, J.-Y. Ahn, K.-Y. Hwang, I. L.-K. Kim, and H. Inseong, "Atmospherically stable nanoscale zero-valent iron particles formed under controlled air contact: Characteristics and reactivity," Environmental Science and Technology, vol. 44, no. 5, pp. 1760-1766, 2010.

[36] Y. Zou, X. Wang, A. Khan et al., "Environmental Remediation and Application of Nanoscale Zero-Valent Iron and Its Composites for the Removal of Heavy Metal Ions: A Review," Environmental Science and Technology, vol. 50, no. 14, pp. 72907304, 2016.

[37] R. A. Crane and T. B. Scott, "Nanoscale zero-valent iron: future prospects for an emerging water treatment technology," Journal of Hazardous Materials, vol. 211-212, pp. 112-125, 2012.

[38] Y. Zhang, W. Chen, C. Dai, C. Zhou, and X. Zhou, "Structural evolution of nanoscale zero-valent iron (nZVI) in anoxic Co $2+$ solution: Interactional performance and mechanism," Scientific Reports, vol. 5, Article ID 13966, 2015.

[39] V. Zolla, F. S. Freyria, R. Sethi, and A. Di Molfetta, "Hydrogeochemical and biological processes affecting the long-term performance of an iron-based permeable reactive barrier," Journal of Environmental Quality, vol. 38, no. 3, pp. 897-908, 2009.

[40] R. W. Gillham and S. F. O'Hannesin, "Enhanced degradation of halogenated aliphatics by zero valent iron," Ground Water, vol. 32, no. 6, pp. 958-967, 1994.

[41] X.-Q. Li, D. W. Elliott, and W.-X. Zhang, "Zero-valent iron nanoparticles for abatement of environmental pollutants: materials and engineering aspects," Critical Reviews in Solid State and Materials Sciences, vol. 31, no. 4, pp. 111-122, 2006.

[42] S. H. Joo, A. J. Feitz, and T. D. Waite, "Oxidative Degradation of the Carbothioate Herbicide, Molinate, Using Nanoscale ZeroValent Iron," Environmental Science and Technology, vol. 38, no. 7, pp. 2242-2247, 2004.

[43] V. Addorisio, D. Pirozzi, S. Esposito, and F. Sannino, "Decontamination of waters polluted with simazine by sorption on mesoporous metal oxides," Journal of Hazardous Materials, vol. 196, pp. 242-247, 2011.

[44] J. Klausen, J. Ranke, and R. P. Schwarzenbach, "Influence of solution composition and column aging on the reduction of nitroaromatic compounds by zero-valent iron," Chemosphere, vol. 44, no. 4, pp. 511-517, 2001.

[45] S.-W. Jeen, D. W. Blowes, and R. W. Gillham, "Performance evaluation of granular iron for removing hexavalent chromium under different geochemical conditions," Journal of Contaminant Hydrology, vol. 95, no. 1-2, pp. 76-91, 2008.

[46] J. Cao, L. Wei, Q. Huang, L. Wang, and S. Han, "Reducing degradation of azo dye by zero-valent iron in aqueous solution," Chemosphere, vol. 38, no. 3, pp. 565-571, 1999.

[47] M.-C. Chang, H.-Y. Shu, H.-H. Yu, and Y.-C. Sung, "Reductive decolourization and total organic carbon reduction of the diazo dye CI Acid Black 24 by zero-valent iron powder," Journal of Chemical Technology and Biotechnology, vol. 81, no. 7, pp. 12591266, 2006.

[48] C. Noubactep, "Characterizing the discoloration of methylene blue in $\mathrm{Fe} 0 / \mathrm{H} 2 \mathrm{O}$ systems," Journal of Hazardous Materials, vol. 166, no. 1, pp. 79-87, 2009.

[49] M. Hou, F. Li, X. Liu, X. Wang, and H. Wan, "The effect of substituent groups on the reductive degradation of azo dyes by zerovalent iron," Journal of Hazardous Materials, vol. 145, no. 12, pp. 305-314, 2007.

[50] S. Nam and P. G. Tratnyek, "Reduction of azo dyes with zerovalent iron," Water Research, vol. 34, no. 6, pp. 1837-1845, 2000. 
[51] Y. He, J.-F. Gao, F.-Q. Feng, C. Liu, Y.-Z. Peng, and S.-Y. Wang, "The comparative study on the rapid decolorization of azo, anthraquinone and triphenylmethane dyes by zero-valent iron," Chemical Engineering Journal, vol. 179, pp. 8-18, 2012.

[52] G. Roy, P. De Donato, T. Görner, and O. Barres, "Study of tropaeolin degradation by iron - Proposition of a reaction mechanism," Water Research, vol. 37, no. 20, pp. 4954-4964, 2003.

[53] Y. Zhuang, L. Jin, and R. G. Luthy, "Kinetics and pathways for the debromination of polybrominated diphenyl ethers by bimetallic and nanoscale zerovalent iron: Effects of particle properties and catalyst," Chemosphere, vol. 89, no. 4, pp. 426432, 2012.

[54] J. E. Martin, A. A. Herzing, W. Yan et al., "Determination of the oxide layer thickness in core-shell zerovalent iron nanoparticles," Langmuir, vol. 24, no. 8, pp. 4329-4334, 2008.

[55] J. T. Nurmi, P. G. Tratnyek, V. Sarathy et al., "Characterization and properties of metallic iron nanoparticles: spectroscopy, electrochemistry, and kinetics," Environmental Science and Technology, vol. 39, no. 5, pp. 1221-1230, 2005.

[56] Y.-P. Sun, X.-Q. Li, J. Cao, W.-X. Zhang, and H. P. Wang, "Characterization of zero-valent iron nanoparticles," Advances in Colloid and Interface Science, vol. 120, no. 1-3, pp. 47-56, 2006.

[57] A. Liu, J. Liu, J. Han, and W. Zhang, "Evolution of nanoscale zero-valent iron (nZVI) in water: Microscopic and spectroscopic evidence on the formation of nano- and microstructured iron oxides," Journal of Hazardous Materials, vol. 322, pp. 129-135, 2017.

[58] L. Signorini, L. Pasquini, L. Savini et al., "Size-dependent oxidation in iron/iron oxide core-shell nanoparticles," Physical Review B, vol. 68, no. 19, Article ID 195423, 2003.

[59] C. Wang, D. R. Baer, J. E. Amonette, M. H. Engelhard, J. Antony, and Y. Qiang, "Morphology and electronic structure of the oxide shell on the surface of iron nanoparticles," Journal of the American Chemical Society, vol. 131, no. 25, pp. 8824-8832, 2009.

[60] C.-B. Wang and W.-X. Zhang, "Synthesizing nanoscale iron particles for rapid and complete dechlorination of TCE and PCBs," Environmental Science and Technology, vol. 31, no. 7, pp. 2154-2156, 1997.

[61] W. Yan, A. A. Herzing, C. J. Kiely, and W.-X. Zhang, "Nanoscale zero-valent iron (nZVI): aspects of the core-shell structure and reactions with inorganic species in water," Journal of Contaminant Hydrology, vol. 118, no. 3-4, pp. 96-104, 2010.

[62] R. Mukherjee, R. Kumar, A. Sinha, Y. Lama, and A. K. Saha, "A review on synthesis, characterization, and applications of nano zero valent iron (nZVI) for environmental remediation," Critical Reviews in Environmental Science and Technology, vol. 46, no. 5, pp. 443-466, 2016.

[63] Y. S. El-Temsah and E. J. Joner, "Effects of nano-sized zerovalent iron (nZVI) on DDT degradation in soil and its toxicity to collembola and ostracods," Chemosphere, vol. 92, no. 1, pp. 131-137, 2013.

[64] Y. S. El-Temsah and E. J. Joner, "Ecotoxicological effects on earthworms of fresh and aged nano-sized zero-valent iron (nZVI) in soil," Chemosphere, vol. 89, no. 1, pp. 76-82, 2012.

[65] B. H. Toby, "EXPGUI, a graphical user interface for GSAS," Journal of Applied Crystallography, vol. 34, no. 2, pp. 210-213, 2001.

[66] S. Momeni and D. Nematollahi, "New insights into the electrochemical behavior of acid orange 7: Convergent paired electrochemical synthesis of new aminonaphthol derivatives," Scientific Reports, vol. 7, p. 41963, 2017.

[67] B. A. Balko and P. G. Tratnyek, "Photoeffects on the reduction of carbon tetrachloride by zero-valent iron," Journal of Physical Chemistry B, vol. 102, no. 8, pp. 1459-1465, 1998.

[68] E. Shafia, S. Esposito, M. Armandi, E. Bahadori, E. Garrone, and B. Bonelli, "Reactivity of bare and Fe-doped alumino-silicate nanotubes (imogolite) with $\mathrm{H} 2 \mathrm{O} 2$ and the azo-dye Acid Orange 7," Catalysis Today, vol. 277, pp. 89-96, 2016.

[69] E. Shafia, S. Esposito, M. Armandi, M. Manzoli, E. Garrone, and B. Bonelli, "Isomorphic substitution of aluminium by iron into single-walled alumino-silicate nanotubes: A physico-chemical insight into the structural and adsorption properties of $\mathrm{Fe}$ doped imogolite," Microporous and Mesoporous Materials, vol. 224, pp. 229-238, 2016.

[70] O. Karaagac and H. Kockar, "Iron oxide nanoparticles coprecipitated in air environment: Effect of $[\mathrm{Fe}+2] /[\mathrm{Fe}+3]$ ratio," IEEE Transactions on Magnetics, vol. 48, no. 4, pp. 1532-1536, 2012.

[71] S. A. Kahani and M. Jafari, "A new method for preparation of magnetite from iron oxyhydroxide or iron oxide and ferrous salt in aqueous solution," Journal of Magnetism and Magnetic Materials, vol. 321, no. 13, pp. 1951-1954, 2009.

[72] G. Socrates, Infrared and Raman Characteristic Group Frequencies, Chichester, UK, 2004. 

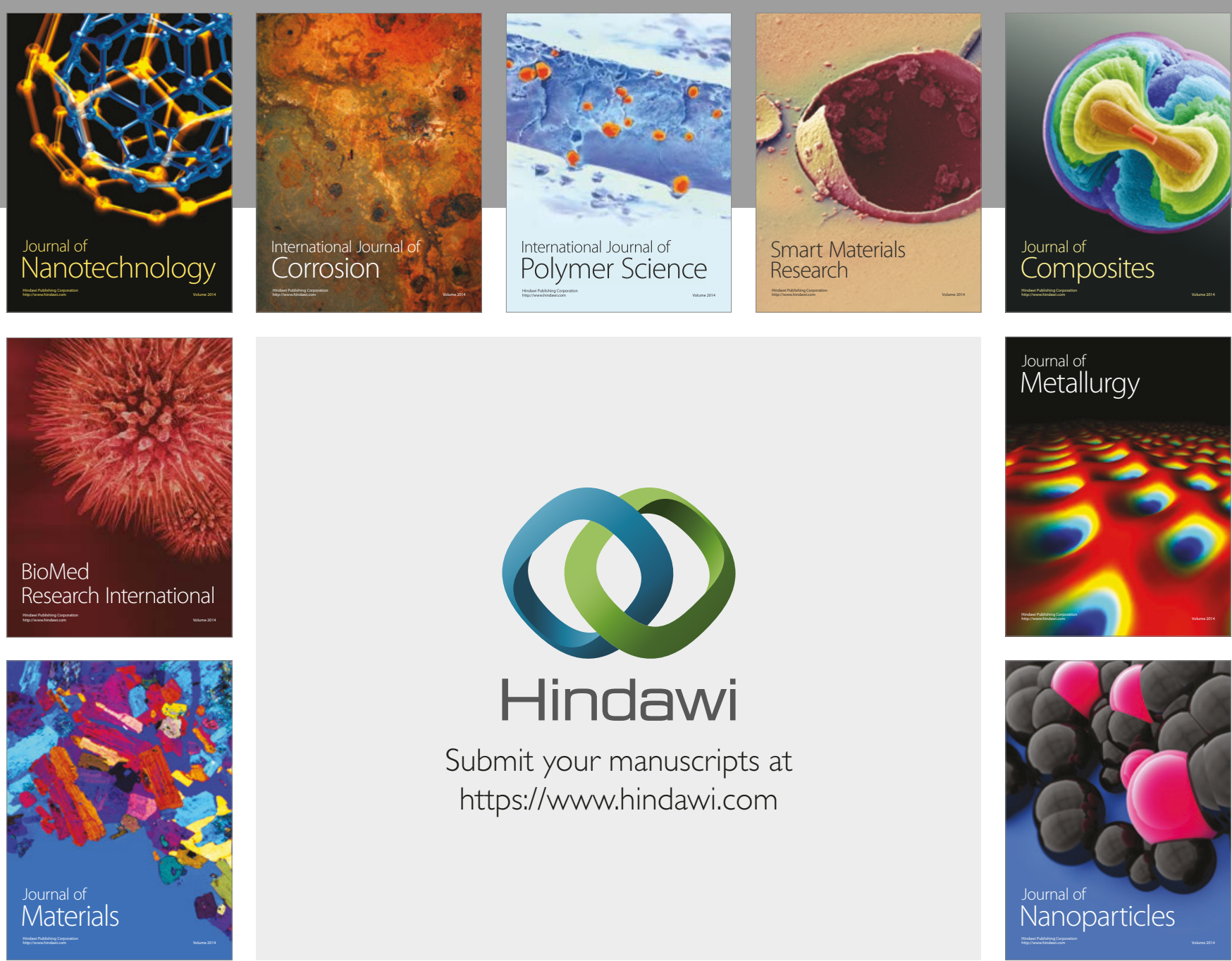

\section{Hindawi}

Submit your manuscripts at

https://www.hindawi.com
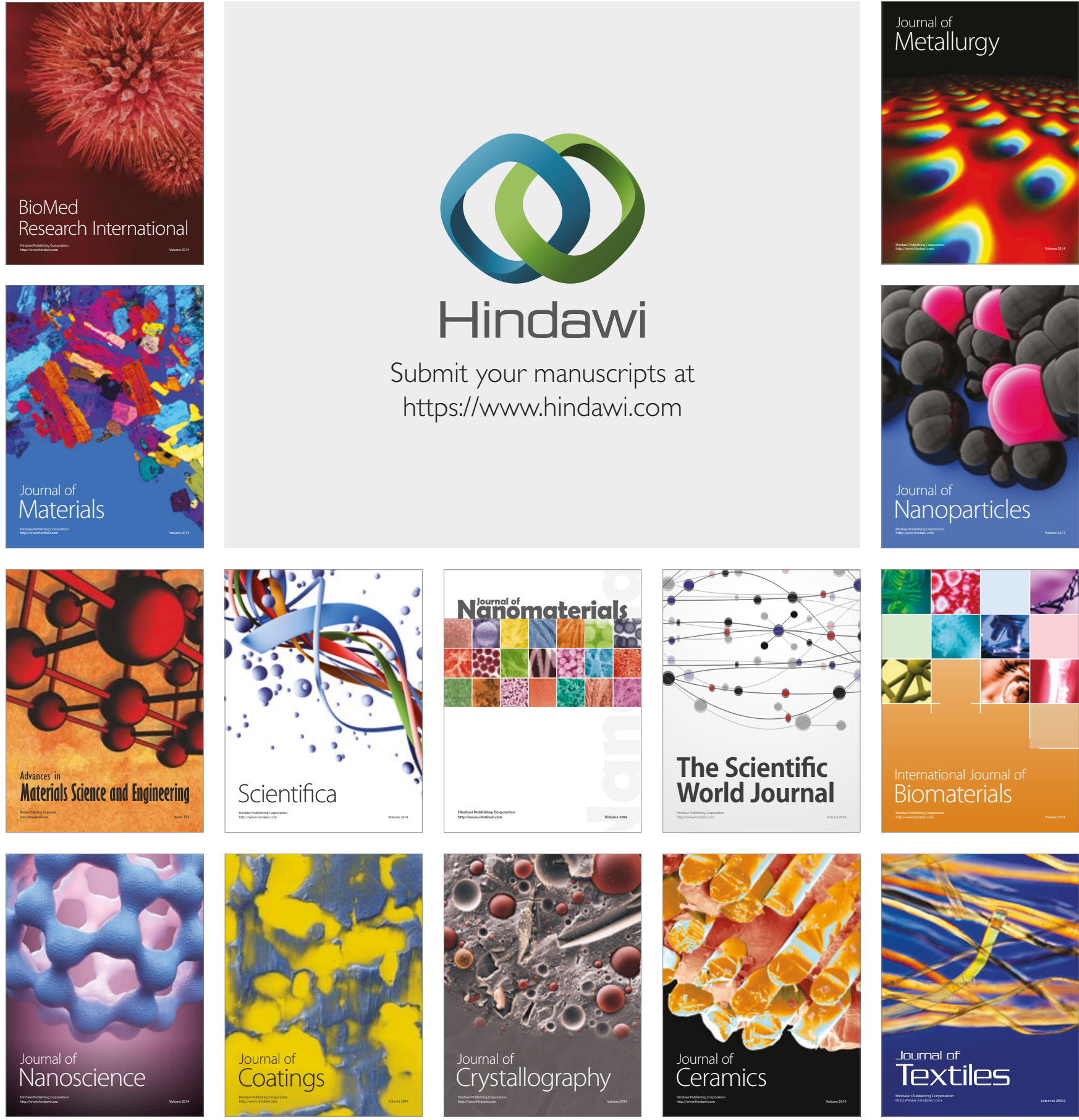

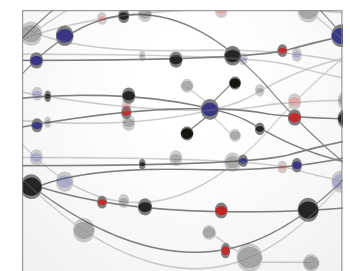

The Scientific World Journal
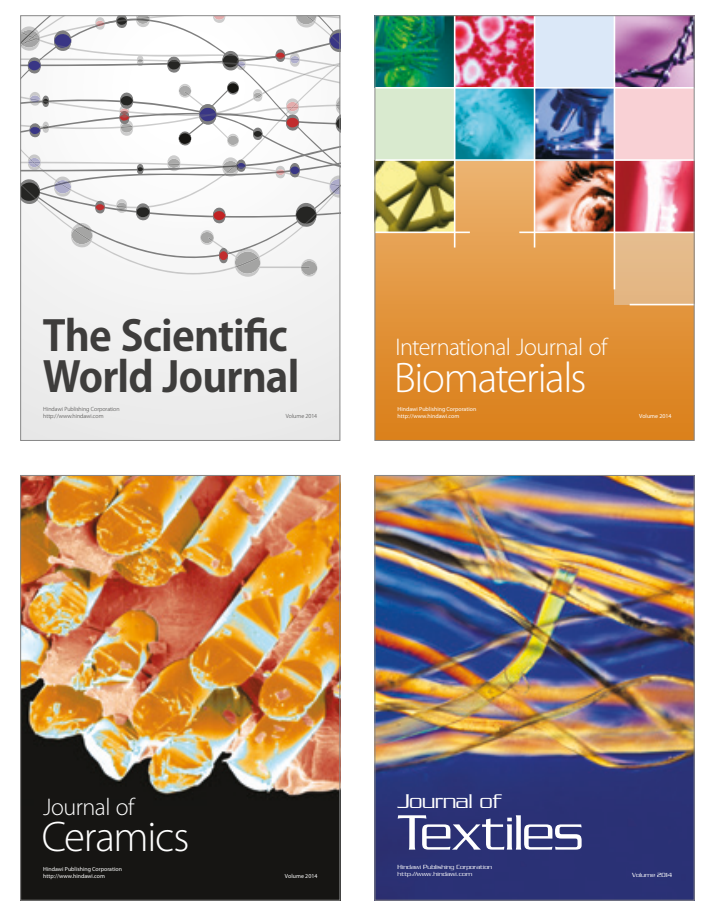